Int. J. Dev. Biol. 59: 187-194 (2015)

doi: $10.1387 / \mathrm{ijdb} .140190 \mathrm{LS}$

\title{
Gliolectin positively regulates Notch signalling during wing-vein specification in Drosophila
}

\author{
NAVEEN PRASAD* and LINGADAHALLI S. SHASHIDHARA \\ Indian Institute of Science Education and Research (IISER), Pune, India
}

\begin{abstract}
Notch signalling is essential for animal development. It integrates multiple pathways controlling cell fate and specification. Here we report the genetic characterization of Gliolectin, presumably a lectin, a cytoplasmic protein, significantly enriched in Golgi bodies. Its expression overlaps with regions where Notch is activated. Loss of gliolectin function results in ectopic veins, while gain of its function causes loss of wing veins. It positively regulates Enhancer of $s p l i t m \beta$, a target of Notch signalling. These observations suggest that it is a positive regulator of Notch signalling during wing development in Drosophila.
\end{abstract}

KEY WORDS: Glec, Notch, wing vein development, D/V boundary

\section{Introduction}

Signalling pathways interact at different stages of development to give rise to a flattened wing in the adult Drosophila, starting from a monolayer sheet of cells called the wing imaginal disc. The five longitudinal veins found in Drosophila wings are positioned in the late third larval instar wing disc by the activity of numerous signalling pathways (reviewed by Blair, 2007). During wing disc patterning, Rhomboid (Rho), a membrane protein is expressed in stripes of cells that develop later into veins (Sturtevant et al., 1993). Rho interacts with Epidermal Growth Factor Receptor (EGFR) (Price et al., 1989; Sturtevant et al., 1993) leading to activation of the EGFR signalling pathway. Activation of Ras/EGFR signalling pathway in presumptive vein territories directs these cells into a vein differentiation pathway (Gabay et al., 1997; Diaz-Benjumea et al., 1990; De Celis, 1998; De Celis and Diaz-Benjumea, 2003). Vein differentiation continues during pupal development and involves the restriction of specific gene products and cell adhesion proteins to veins or intervein territories (Fristrom et al., 1993; Montagne et al., 1996).

Notch $(\mathrm{N})$ signalling is involved in establishing the correct width of various wing veins (de Celis et al., 1994). Delta (DI), a ligand that activates $\mathrm{N}$, is found at higher levels in the provein regions resulting in the activation of $\mathrm{N}$ in the intervein regions (de Celis et al., 1997b). Loss of $N$ alleles display vein thickening in the wing and enhanced rho expression, while gain of function of $N$ show thinner and incomplete veins with reduced or lost rho expression
(Palka et al., 1990; de celis et al., 1994; Sturtevant et al., 1995; de Celis et al., 1997b).

Expression of $D /$ is under the transcriptional control of EGFR signalling pathway (Simcox et al., 1996; Schnepp et al., 1996; de Celis et al., 1997b) whereas the expression of $N$ is independent of the formation of wing veins (de Celis et al., 1997b). In the absence of $\mathrm{DI}, \mathrm{N}$ is not activated and hence is unable to activate its downstream targets (de Celis et al., 1997b). The $\mathrm{N}$ target gene Enhancer of split $\mathrm{m} \beta(\mathrm{E}(\mathrm{Spl}) \mathrm{m} \beta)$ represses rho expression when ectopically expressed in the wing imaginal disc and thus mimics gain of function of $\mathrm{N}$. This is further confirmed by the fact that loss of vein phenotype caused by ectopic expression of $E(S p l) m \beta$ can be rescued by the simultaneous ectopic expression of Rho (de Celis et al.,1997b). Expression of $\mathrm{E}(\mathrm{Spl}) \mathrm{m} \beta$ in the wing imaginal discs is complementary to that of $\mathrm{DI}$, being maximal in the presumptive intervein regions and low in the veins. As $E(S p l) m \beta$ is not expressed in the vein territory, the repression of $r h o$ (expressed in the presumptive veins) by $\mathrm{N}$ target gene $\mathrm{E}(\mathrm{Spl}) \mathrm{m} \beta$ must be indirect (de Celis et al.,1997b). This mechanism restricts the regions (presumptive veins) where rho is expressed (Sturtuvent et al., 1995; de Celis et al., 1997b). Thus, $\mathrm{N}$ maintains the correct width of the veins by inhibiting vein development in the intervein cells.

An allele of glec ( lec $^{\text {d04956}}$ ) has been shown to enhance the notched wing phenotype of $N$ allele $\left(N^{54 L 9}\right)$ (Hurlbut et al., 2009). In

Abbreviations used in this paper: D/V, dorso/ventral; Rho, rhomboid.

\footnotetext{
*Address correspondence to: Naveen Prasad. Indian Institute of Science Education and Research (IISER) Pune, Pashan Road, Pune 411008, India.

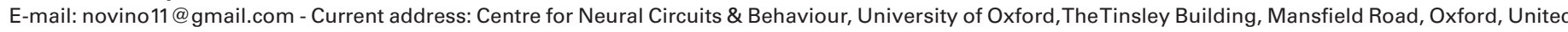
Kingdom, OX1 3SR
}

Supplementary Material for this paper is available at: http://dx.doi.org/10.1387/ijdb.140190LS

Accepted: 4 March 2015.

ISSN: Online 1696-3547, Print 0214-6282 


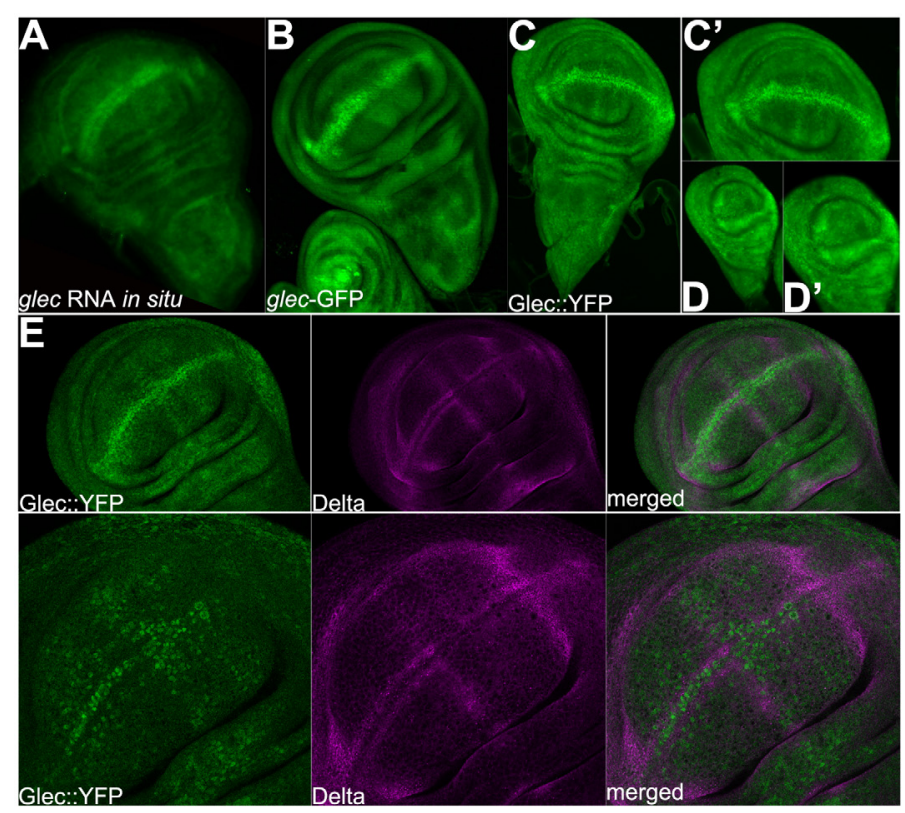

this study we report that gliolectin (glec) is required for specification of vein/intervein regions in the Drosophila wing. We show that glec is expressed in the regions of wing imaginal disc where $N$ is activated. Loss of function of glec shows ectopic veins, while gain of function of glecshows loss of wing vein. Glec positively regulates members of $N$ signalling pathway and interacts with components of EGFR signalling pathway. Owing to its biochemical nature as a carbohydrate binding protein (Tiemeyer et al., 1996) and its presence in Golgi bodies in the regions where $\mathrm{N}$ is activated, we propose that Glec might be modifying certain components of the $N$ signalling cascade.

\section{Results and Discussion}

\section{Glec is expressed in the $D / V$ boundary in the wing imaginal disc}

Differential expression of glecbetween wing and haltere has been shown earlier by RNA in situ (Prasad et al., 2006; Fig. 1A). First we tested expression of protein trap lines of Glec. The Glec:YFP (DGRC Kyoto) and the glec-GFP (Enhancer Trap) show that although Glec is expressed at low levels ubiquitously in the entire wing imaginal disc, maximal expression of the protein is seen in the dorsal ventral (D-V) boundary (Fig. 1B).

$\mathrm{DI}$ is expressed in the proveins in the third larval wing disc and also along two stripes adjoining the $\mathrm{D}-\mathrm{V}$ boundary (Huppert et al., 1997, de Celis et al., 1997a,b). Double staining of Glec

Fig. 2. Expression of Glec along the D-V boundary and its localisation in the Golgi bodies. (A) Glec:: YFP wing disc triple stained for YFP (green), Ct (red) and DAPI (magenta). Glec expression overlaps with that of $\mathrm{Ct}$ in the DN boundary. (B,C) Glec:: YFP Wing disc triple stained for YFP (green), Wg (red) and DAPI (magenta). Glec expression overlaps with that of $\mathrm{Wg}$ in the DN boundary. (C) Magnified image of the D-V boundary. Note that Glec is neither present on the plasma membrane nor in the nucleus. (D) Glec:: YFP wing imaginal disc double stained for YFP (green) and Galt (magenta). Please note co-localization of Glec and Galt (a marker for Golgi bodies) suggesting that Glec is a Golgi-localized protein.
Fig. 1. Expression pattern of Glec in the wing imaginal disc. (A) Wild type wing disc showing Glec expression as determined by RNA in situ hybridization. (B) Wing disc of glec-GFP enhancer trap line showing GFP expression pattern. (C,D) Wing (C) and haltere (D) discs of Glec::YFP stained forYFP ( $C^{\prime}$ and $D$ ' show the discs at highermagnification). Glec is expressed predominantly along the $D-V$ axis of the wing imaginal discs. Please note the absence of Glec along the D-V boundary in the haltere imaginal disc las reported by Prasad et al., 2006). (E) Wing imaginal disc of Glec::YFP double stained for YFP (green) and DI (magenta). Upper panel is at magnification $25 X$, while bottom panel is the same disc at 63X magnification. Note that expression patterns of Glec and Delta are mutually exclusive.

with $\mathrm{DI}$ indicates a complementary expression pattern in the wing pouch (Fig. 1E). Along the D/V axis, $\mathrm{N}$ activates $\mathrm{Ct}$ and $\mathrm{Wg}$ in the D-V boundary (deCelis et al., 1997a). Glec expression overlaps with that of $\mathrm{Wg}$ and $\mathrm{Ct}$, although Glec is also expressed in cells abutting the D-V boundary (Fig. 2 A-C).

\section{Presence of Glec in Golgi bodies}

We then examined the sub cellular localization of Glec. Triple staining for Wg, Glec and DAPI suggested that Glec is present as punctate structures in the entire cell but is not present near or on the plasma membrane (Fig. 2C). Mouse homolog of glec, GM3 synthase localizes to the Golgi bodies of neurons (Stern et al., 2000). We therefore examined the co-localisation of Glec with Galactosyl transferase (Galt), a Golgi body marker in the wing imaginal disc. The co-localization suggests that Glec is present in the Golgi bodies, although not exclusively (Fig. 2D).

\section{Glec functions to restrict wing vein development}

To enable spatio-temporal down regulation of glec, we generated two different transgenic RNAi lines that would generate double stranded RNA targeting non-overlapping regions of glec mRNA -

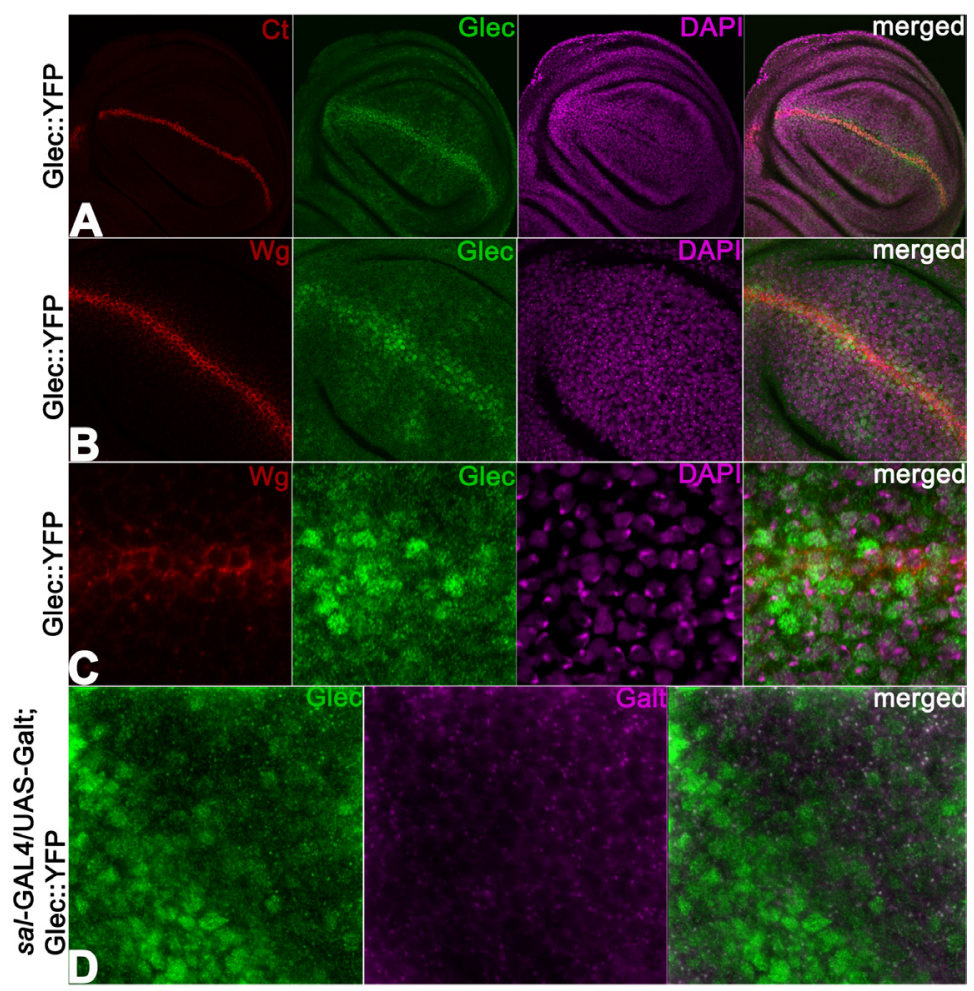


one targeting 5' end, while the other targeting the 3' end. To test the efficacy of these RNAi lines, we crossed them to sal-GAL4 driver in a background of Glec::YFP fusion lines. The expression of Glec was reduced considerably in the domain of sal-GAL4 and both the RNAi lines were equally efficient in down regulating glec expression (Fig. $3 \mathrm{~A}-\mathrm{C}$ ). All the experiments were independently

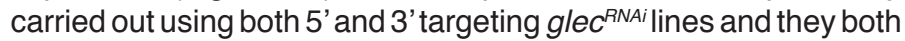
generated identical phenotypes. In the text we would be referring to these lines as glec ${ }^{\text {RNAi }}$ line.

Upon down regulation of glec using UAS-glec ${ }^{\text {RNAi }}$ (driven by MS1096-GAL4 driver), we observed ectopic veins in regions close to different longitudinal veins (Fig.3: $D$-E; penetrance 30\%, $n=176$ at $28{ }^{\circ} \mathrm{C}$ ). This phenotype was also seen when glec was down regulated using ap-GAL4 driver (data not shown; penetrance 81 $\%$ at $28^{\circ} \mathrm{C}, \mathrm{n}=20$; down-regulation was also associated with considerable lethality). The penetrance of the phenotype was higher when down regulation was carried out using two copies of $g l e c^{\text {RNAi }}$ driven by MS1096-GAL4 at $28{ }^{\circ} \mathrm{C}$ (penetrance $39 \%$ at $25^{\circ} \mathrm{C}, \mathrm{n}=$ 73 and $74 \%$ at $28{ }^{\circ} \mathrm{C}, \mathrm{n}=135$ ). We also used VDRC RNAi lines to down regulate glec using MS1096-GAL4 driver under similar conditions and observed identical phenotypes (data not shown; penetrance $64 \%$ at $28{ }^{\circ} \mathrm{C}, \mathrm{n}=72$ ). However, the VDRC lines had two off targets and hence to avoid any discrepancies, we only used

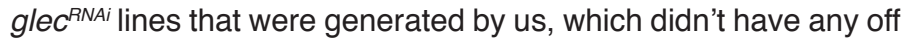
targets, for further experiments.
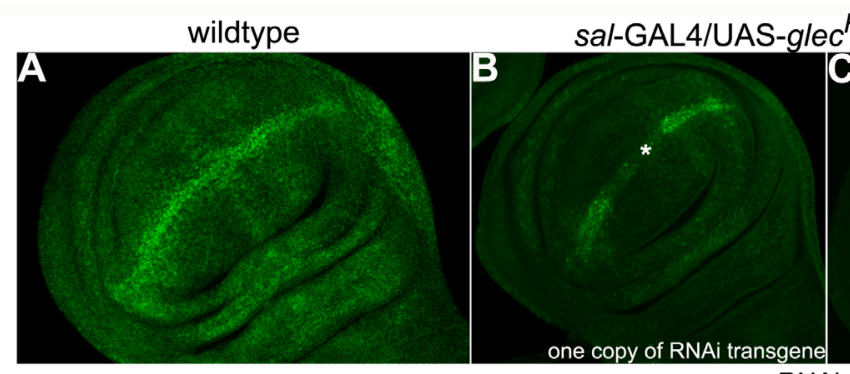

$c^{R N A i}$.

; Glec::YFP

wildtype

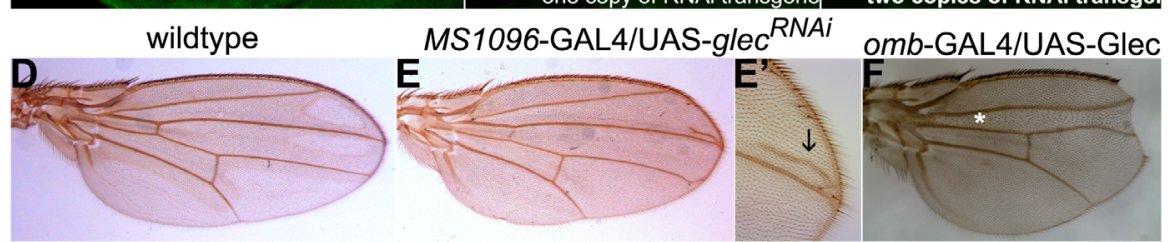

MS1096-GAL4/UAS-glec ${ }^{R N A i}$
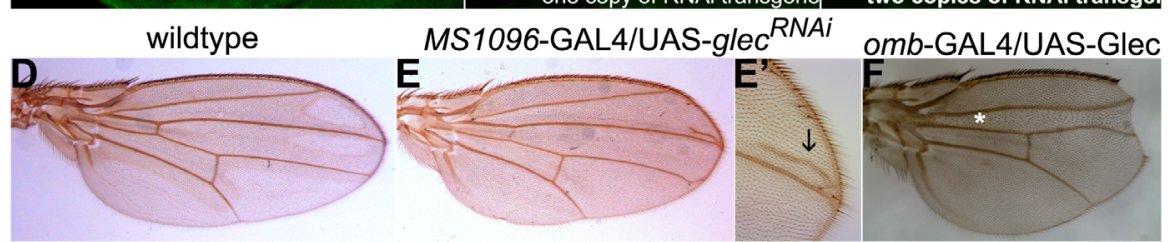

two copies of RNAi transge

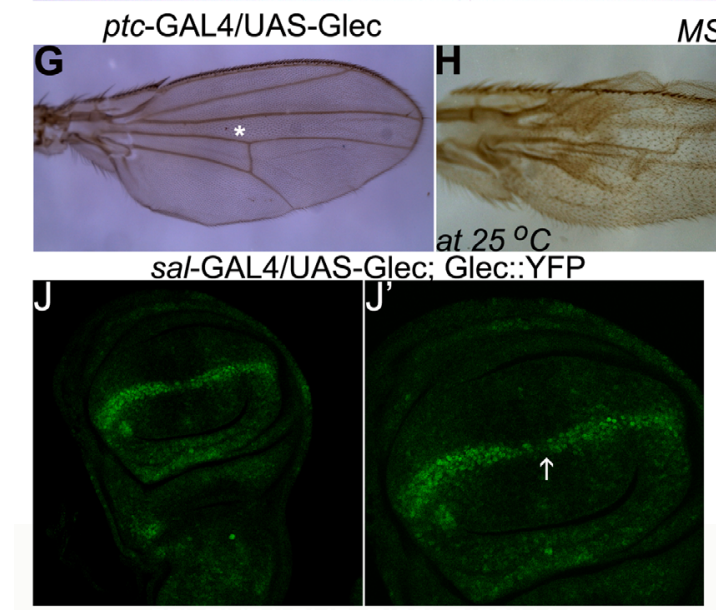

MS1096-GAL4/UAS-Glec

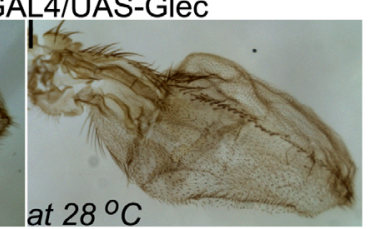

Fig. 3. Loss of Glec causes ectopic wing vein development. (A) Glec::YFP wing disc

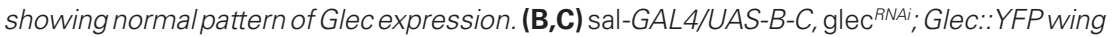
discs showing down regulation of glec along $A$-P axis (asterix). (B) shows down regulation of Glec using one copy of the transgene and (C) shows with two copies of the transgene, both grown at $28^{\circ} \mathrm{C}$. (D,E) Adult wing blades of wildtype (D) and MS1096-GAL4/UAS-glec ${ }^{\text {RNAi }}$ (E) flies, both grown at $28^{\circ} \mathrm{C}$. Note ectopic vein close to L3 in E (arrow). (F-I) Adult wing blades of flies over-expressing Glec using UAS-glec and omb- (F), ptc- (G) and MS1096- (H, I) GAL4 drivers. Note loss of anterior-cross vein (asterix) in $(F, G)$ and complete loss of wing veins in $(H, I)$. The experiment was carried out at $28^{\circ} \mathrm{C}$ in ( $F, G$ and I) and at $25^{\circ} \mathrm{C}$ in (H). MS1096-GAL4 expresses in the dorsal compartment. (J) Wing disc of sal-GAL4/UAS-Glec; Glec::YFP grown at $28^{\circ} \mathrm{C}$. A reduction in Glec expression in the centre of the wing pouch (arrow), suggests negative feedback loop. 
down regulation of its expression in dorsal compartment of the wing imaginal disc in response to down regulation of glec using MS1096-GAL4 driver (Fig. 4B).

When over-expressed using MS1096-GAL4, Glec caused increased levels of $E(S p l) m \beta$ in the ventral compartment (Fig. $4 C)$. We observed higher levels of $E(S p l) m \beta$ in the anterior side of the ventral compartment and in the intervein between L 3 and L4 (Fig. 4C). Intriguingly, we found that the levels of $E(S p l) m \beta$ was significantly reduced in the dorsal compartment. We attribute this discrepancy to the variation in spatio-temporal expression pattern of GAL4 line used for this study. MS1096-GAL4 is strongly expressed in the dorsal compartment of the wing imaginal disc, which begins from early third instar larval stage, while its expression in the ventral compartment starts from late third larval instar stage and levels are much lower than in the dorsal compartment (Wang et al., 1999). This could be the reason for the effect of RNAimediated down regulation of glec on $E(S p l) m \beta$ was detectable only in the dorsal compartment.

If Glec positively regulate $\mathrm{N}$ signalling, its ectopic expression in the dorsal compartment in the early third instar larval stage would activate $\mathrm{N}$, which in turn would increase the levels of $E(S p l) m \beta$. However, prolonged strong activation of $\mathrm{N}$ may have negative impact on its own signalling. Activation of $\mathrm{N}$ would result in the down regulation of EGFR/Ras signalling in the early third instar larva. As $D I$ is under the transcriptional control of the EGFR/Ras signalling pathway, loss of EGFR/Ras signalling would reduce the expression of $D I$, which in turn would lead to decreased activation of $\mathrm{N}$, resulting in reduced expression of $E(S p l) m \beta$ expression.

Another possibility is, Glec is negatively auto-regulated when it is over-expressed, leading to loss of $\mathrm{N}$ signalling and increased EGFR signalling. This could be the reason for the observed low levels of $E(S p l) m \beta$ expression in the dorsal compartment. As overexpression of Glec in the ventral compartment is only in the later stages of the third larval instar stages, we may have been able to observe increased levels of $E(S p l) m \beta$, reflecting the role of Glec as a positive regulator of $\mathrm{N}$ signalling. Consistent with this we also observed activation of $E(S p l) m \beta$ expression on the ventral side of the $\mathrm{D}-\mathrm{V}$ boundary, in the regions where $D I$ is normally expressed (and where $E(S p l) m \beta$ is normally absent).

Earlier studies have shown that $\mathrm{N}$ suppresses the expression of
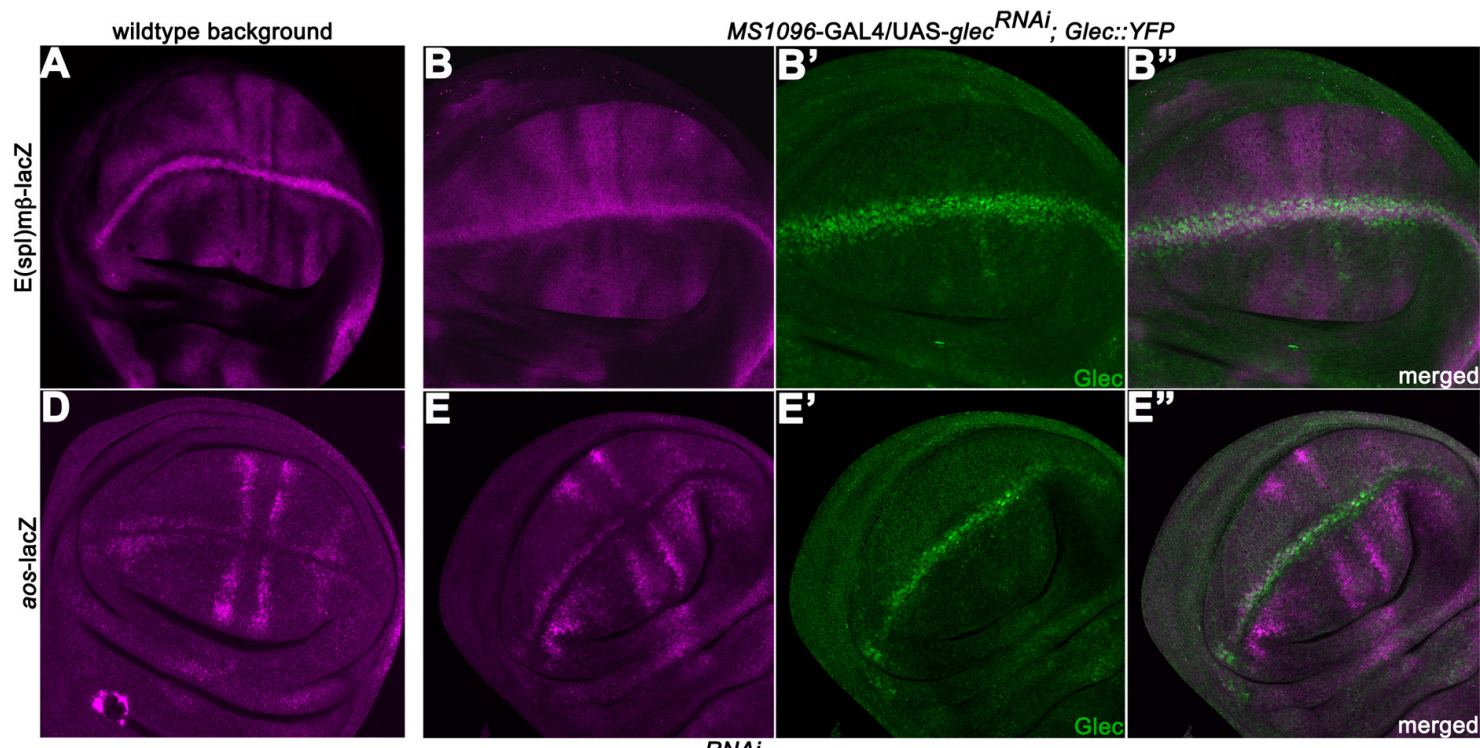

MS1096-GAL4/UAS-Glec
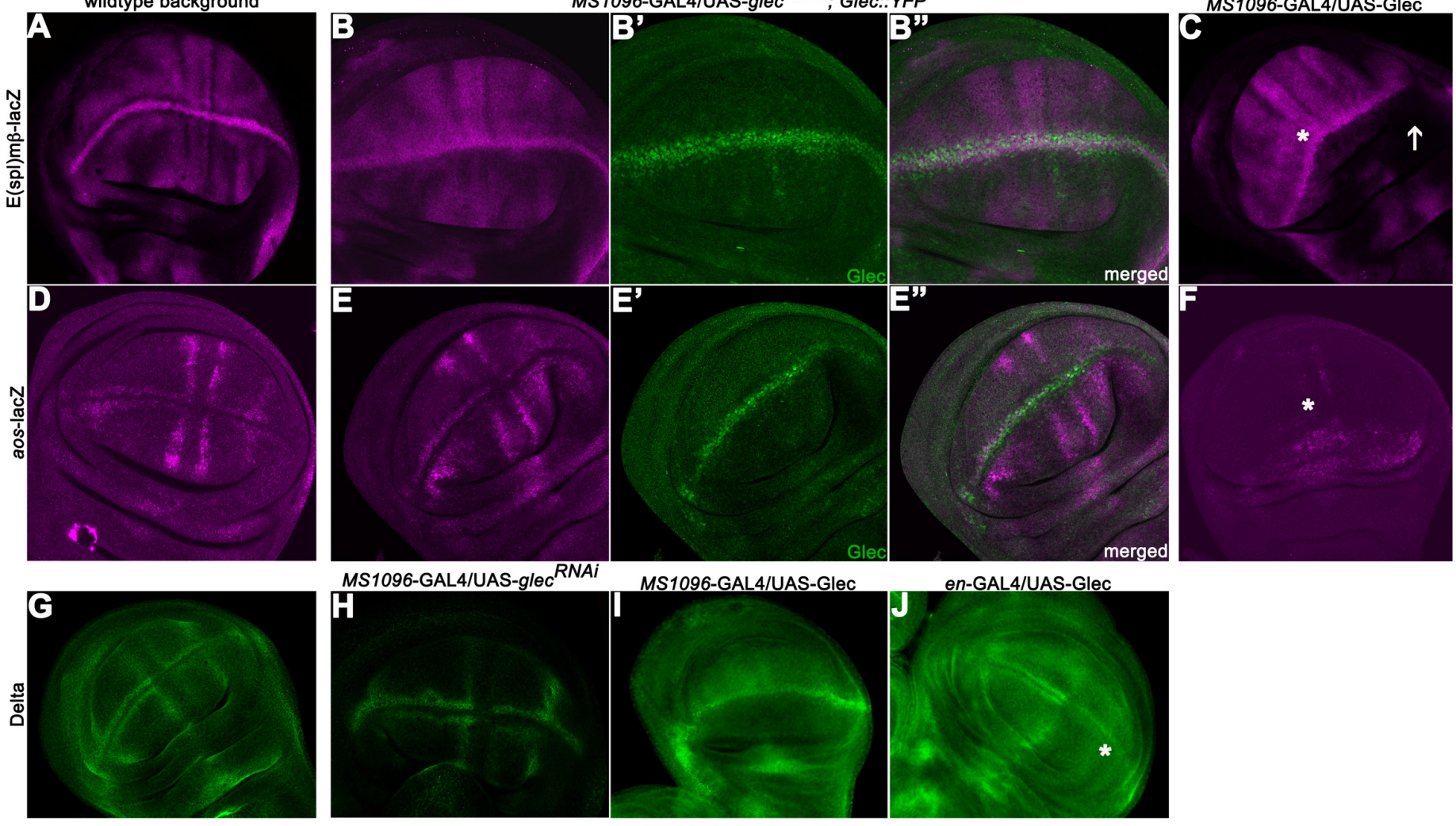

Fig. 4. Glec regulates the expression of $\mathbf{E}(\mathbf{s p l}) \mathbf{m} \boldsymbol{\beta}$. (A) $\mathrm{E}(\mathrm{spl}) \mathrm{m} \beta$-lacZ wing disc stained for $\beta$-galactosidase. In the wild type background, $\mathrm{E}(\mathrm{spl}) \mathrm{m} \beta$ is expressed in the presumptive intervein regions and in the DN boundary. (B) MS1096-GAL4/UAS-glec ${ }^{\text {RNAi; }} \mathrm{E}(\mathrm{spl}) \mathrm{m} \beta$-lacZ/Glec::YFP (raised at $28^{\circ} \mathrm{C}$ ) wing disc stained for YFP (green) and $\beta$-galactosidase (magenta). Note reduced levels of E(spl)m $\beta$-lacZ in the dorsal compartment. (C) MS1096-GAL4/UASGlec; E(spl)m $\beta$-lacZ (raised at $25^{\circ} \mathrm{C}$ ) wing disc stained for $\beta$-galactosidase. Note increased levels of $\mathrm{E}(\mathrm{spl}) \mathrm{m} \beta$-lacZ in the ventral compartment (asterix) and its reduced levels in the dorsal compartment (arrow). (D) aos-lacZ wing disc stained for $\beta$-galactosidase showing Aos expression in the wild type

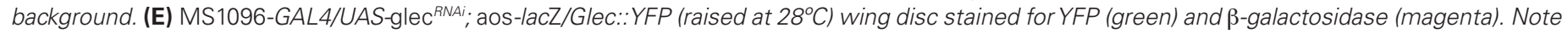
ectopic activation of Aos, but, only in the interviein region. (F) MS1096-GAL4/UAS- Glec; aos-lacZ (raised at 25ㄷ) wing disc. Note ectopic activation of Aos in the dorsal compartment, and its repression in the ventral compartment (asterix). (G-J) Wing discs stained for DI Wildtype (G), MS1096-GAL4/ UAS-glec ${ }^{\text {RNAi }}$ (two copies of RNAi transgene, raised at $28^{\circ} \mathrm{C}$; H), MS1096-GAL4/UAS-Glec (raised at 25 ${ }^{\circ} \mathrm{C}$; I) and en-GAL4/ UAS-GleC (raised at $25^{\circ} \mathrm{C}$; J). Note down regulation of delta along the D-V boundary (but, not in proveins) in (H) and its complete loss in the dorsal compartment in (I). The down regulation of delta is seen only in posterior compartment when Glec is ectopically expressed using en-GAL4 (asterix in J). 

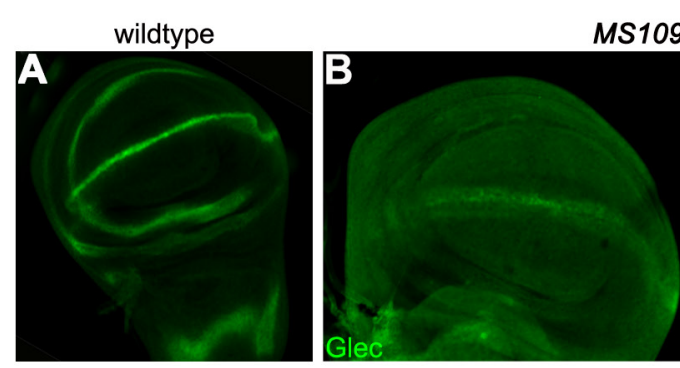

MS1096-GAL4/UAS-glecRNAi; Glec::YFP
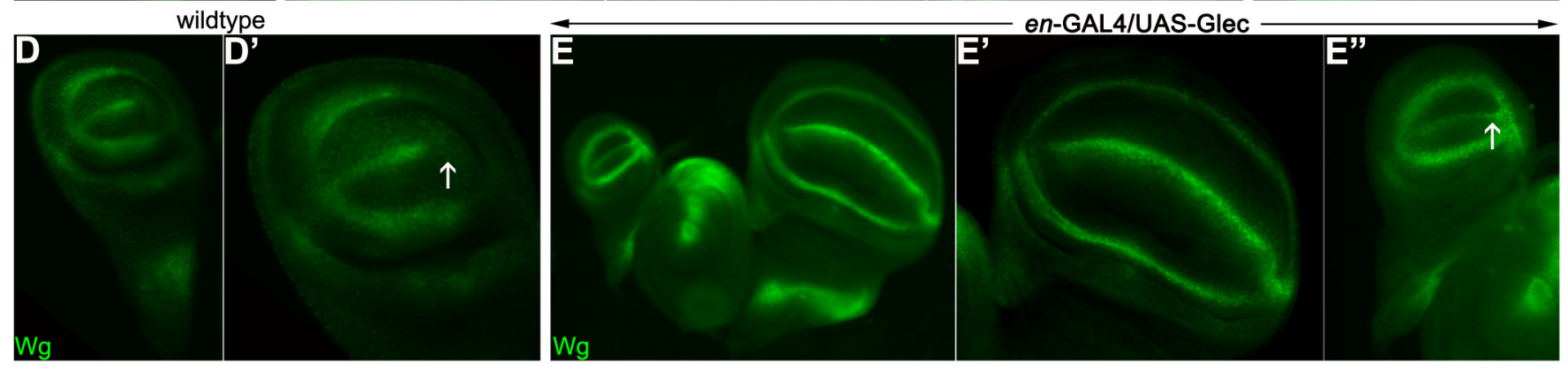

Fig. 5. Glec positively regulates Wg, a target of Notch. Wildtype wing (A) and haltere (D) discs stained for Wg. Note absence of Wg expression in the DN boundary of the posterior compartment of haltere disc (Arrow). (B) MS1096-GAL4/UAS-glec RNAi; Glec::YFP (raised at 28 ${ }^{\circ} \mathrm{C}$ ) wing disC stained for Wg (magenta). No change in Wg expression levels/patterns was observed on reduction of glec transcript. (C) MS1096-GAL4/UAS-Glec (raised at $25^{\circ} \mathrm{C}$ ) and en-GAL4/UAS-Glec (raised at $28^{\circ} \mathrm{C}$ ). Wing (C, E) and haltere discs (E) stained for Wg. (E' , E") The same wing and haltere discs as in (E), but at higher magnification. Note increased levels of Wg in the dorsal compartment of wing disc and in the posterior compartment of haltere disc (Arrow).

EGFR in the presumptive intervein cells. This is by activating the expression of $E(S p l) m \beta$, which in turn represses the expression of components of EGFR in the intervein cells. This helps to keep EGFR expression confined to the presumptive vein cells (de Celis et al., 1997b). We examined the effect of down-regulation of glec on the EGFR pathway by using aos-lacZ, a reporter transgene that directly reflects EGFR activity. We observed upregulation of aoslacZ in the presumptive intervein regions (Fig. 4E) in response to the down-regulation of glec in wing imaginal discs using MS1096GAL4 at $28^{\circ} \mathrm{C}$. Conversely, over-expression of Glec caused down regulation of Aos in presumptive vein regions (Fig. 4F). However, consistent with the effect of over-expression of Glec on the expression pattern of $E(S p l) m \beta$, we also observed increased levels of aos-lacZ in the dorsal compartment.

$D /$ plays an important role in the cross talk between EGFR and $\mathrm{N}$ pathways. In the vein-intervein specification, $\mathrm{Dl}$ is expressed in the presumptive vein regions, which is directly regulated by the EGFR singling pathway at the transcriptional level, while it acts as a ligand to activate $\mathrm{N}$ in the adjacent intervein regions. However, along the DV axis, $\mathrm{N}$ signalling positively regulates $\mathrm{DI}$ expression (de Celis et al., 1997a). Consistent with this mode of interactions, we observed loss of DI in dorsal cells adjacent to the D/V boundary when glec is down regulated using MS1096-GAL4 driver. However, loss of glec did not affect DI expression in the proveins. Even when glec was down regulated with two copies of $g_{l e c^{R N A i}}$ transgenes using MS1096-GAL4 at $28{ }^{\circ} \mathrm{C}$, we did not see any effect on DI expression in the proveins, while its expression was further down regulated along the $\mathrm{D} / \mathrm{V}$ boundary compared to when single copy of glec $^{R N A i}$ transgene was used. This suggests that Glec is primarily a regulator of $\mathrm{N}$ pathway, and the observed effect on EGFR/Ras pathway is due to down regulation of $\mathrm{N}$ pathway (Fig. $4 \mathrm{H}$ ).

Over-expression of Glec using MS1096- or en-GAL4 driver at $25^{\circ} \mathrm{C}$ down regulated $\mathrm{DI}$ expression (Fig. $\left.4 \mathrm{I}, \mathrm{J}\right)$. This was expected since, as described above, over-expression of Glec in the dorsal compartment during early $3^{\text {rd }}$ instar larval stages would lead to loss of $\mathrm{N}$, either due to negative auto-regulation of Glec itself and/or negative feedback through EGFR pathway.

It is intriguing, while loss of function of glec results in the activation of $N$ signalling pathway, ectopic expression of Glec using MS1096-GAL4 seems to exhibit, in the dorsal compartment of the wing imaginal disc, phenotypes that would resemble down regulation of $N$ leading to ambiguity in conclusions. We have tried to explain these discrepancies on the basis of spatio-temporal differences in expression of MS1096 GAL4 driver between the dorsal and ventral compartment of the wing imaginal disc. This explanation may be considered as an extrapolation of the limited amount of data that we have.

However, a clearer picture emerges if we focus on the ventral compartment of the wing imaginal disc in the cases where Glec is ectopically expressed using MS1096-GAL4 driver. As mentioned earlier, MS1096-GAL4 expression in the ventral compartment begins in the late third instar larval stage and is mild. The effects of Glec over expression using MS1096-GAL4 in the ventral compartment complement the effects induced by its down regulation in the dorsal compartment by the same GAL4 driver.

\section{Glec positively regulates wingless, a target of the Notch pathway}

$\mathrm{N}$ activates the expression of $E(S p l) m \beta$ via $\mathrm{Su}(\mathrm{H})$ (Bailey et al., 1995; Lecourtois et al.,1995). E(Spl)m $\beta$ serves as a repressor of various transcription factors by interaction with Groucho (Gro). $\mathrm{E}(\mathrm{spl})$ proteins, in general and $\mathrm{E}(\mathrm{Spl}) \mathrm{m} \beta$, in particular, are required only for a subset of $\mathrm{N}$ functions. For example, these genes do not mediate the effect of $\mathrm{N}$ in various regions such as the $\mathrm{D}-\mathrm{V}$ boundary per se. Asymmetric distribution of ligands of N, DI and Serrate (Ser) results in the activation of $\mathrm{N}$ only at the $\mathrm{D}-\mathrm{V}$ boundary. Activated $\mathrm{N}$ 
in turn induces the expression of genes like $c t$ and $w g$ along the boundary, which are essential for the growth and differentiation of wing (Rulifson et al., 1995; Couso et al., 1995; Diaz- Benjumea et al., 1995; de Celis et al., 1996; Micchelli, et al., 1997).

We did not observe any change in Wg expression when glec was down regulated using MS1096-, sal- or ptc-GAL4 driver either at $25^{\circ} \mathrm{C}$ or $28{ }^{\circ} \mathrm{C}$ (Fig $5 \mathrm{~B}$ ), although down regulation of glec negatively affects $\mathrm{E}(\mathrm{Spl}) \mathrm{m} \beta$ expression (Fig. 4B). Ectopic expression of Glec using MS1096-GAL4 driver resulted in increased levels of $\mathrm{Wg}$ in the dorsal compartment (Fig. 5C). Levels of $\mathrm{Wg}$ in the dorsal compartment were maximal near the $\mathrm{D}-\mathrm{V}$ boundary and decreased towards the hinge region (unlike the expression of $w g$ in the complete dorsal pouch when an activated form of $\mathrm{N}$ is expressed using ap-GAL4 (Juan et al., 2012). It is likely that under normal circumstances, Glec regulates $\mathrm{N}$ signalling only in the context of intervein specification, while increased levels of Glec may affect the expression of $\mathrm{E}(\mathrm{Spl}) \mathrm{m} \beta$-independent targets of $\mathrm{N}$, such as $\mathrm{Wg}$ in the D/V boundary.

Ectopic expression of Glec using ptc-GAL4 and sal-GAL4 did not activate $\mathrm{Wg}$ or $\mathrm{Ct}$ (data not shown). This appeared contradictory to the results we obtained using MS1096-GAL4 driver. As discussed earlier, Glec is auto-regulated. We, therefore, infer that while using mild GAL4 drivers such as sal-GA4, the feedback loop manages to over ride the effect of exogenous Glec by reducing the amount of endogenous Glec. However, when strong GAL4 drivers are used, exogenous Glec itself might be sufficient to break this feedback loop and starts activating $\mathrm{N}$ targets.

We also ectopically expressed Glec in the posterior compartment of wing imaginal disc using en-GAL4, which is a weaker driver. We did not see any change in the levels of $\mathrm{Wg}$ in the posterior compartment of the wing disc (Fig. 5E). However, we noticed the expression of $\mathrm{Wg}$ at the $\mathrm{D}-\mathrm{V}$ boundary of haltere disc in the posterior compartment, where $\mathrm{Wg}$ is normally repressed (Fig. $5 \mathrm{D}, \mathrm{E})$. We reason that in the wing disc, the total levels of Glec is maintained by the feed back loop operating and hence ectopic expression of Glec in the wing imaginal discs may not show a over expression phenotype at the levels of Wg. However, Glec is not expressed in the haltere discs. When Glec is ectopically expressed in the posterior compartment of the haltere disc, the exogenous Glec must be sufficient to activate the expression of $\mathrm{Wg}$. Once again we noticed only a context specific activation of $\mathrm{Wg}$ and we found ectopic $\mathrm{Wg}$ only in the posterior D/V boundary. This means Glec can activate $W g$ expression only in regions where $\mathrm{N}$ is normally activated. This suggests that Glec may function upstream of $E(S p l)$ and $\mathrm{Su}(\mathrm{H})$, effectors of $\mathrm{N}$ and downstream of $\mathrm{DI}$ and Ser, ligands of N.

The 'gain of function' analysis i.e. over expression of Glec clearly suggests that Glec potentiates N signalling. By contrast, the 'loss of function' experiments involving RNAi lines did not yield precisely complementary results. This could be due to low penetrance and poor efficiency of the RNAi lines. Another interesting possibility might involve an auto-regulatory feedback mechanism that compensates for loss of Glec. A detailed clonal analysis using glec mutants will enable to further substantiate the claim that Glec modulates $\mathrm{N}$ signalling pathway both in the $\mathrm{D}-\mathrm{V}$ and non $\mathrm{D}-\mathrm{V}$ cells of the wing disc.

Glec is predicted to be a carbohydrate binding protein or a lectin (Tiemeyer et al., 1996). A number of proteins are posttranslationally modified in the Golgi bodies. $\mathrm{N}$ is one of the most studied amongst the various proteins that are post-translationally modified in Golgi bodies. At the D-V boundary, the ligands of $\mathrm{N}$, namely $D I$ and Ser are responsible for activating $N$. Once $N$ is produced in the endoplasmic reticulum, it interacts with O-fucosyl transferase and is subsequently transferred to the Golgi body. In the Golgi, it is processed by Furin like convertase and glycosylated by various glycosyl transferases. The extracellular domain of $\mathrm{N}$ protein has multiple glycosylation sites, which are modified in the Golgi bodies (reviewed by Bray, 2006; Fortini, 2009). Thus, the presence of $\mathrm{N}$ ligands at specific locations and modulation of $\mathrm{N}$ by post-translational modification enables specific activity of $\mathrm{N}$ even when its expression pattern is not spatially/temporally modulated. It is possible that Glec is involved in the post-translational modification of $\mathrm{N}$ in the Golgi bodies and thereby making it more sensitive to bind to one of its ligands. Further biochemical characterization is required to identify possible mechanism by which Glec activates $\mathrm{N}$ in the Golgi.

In summary, our observations are consistent with the possibility that $\mathrm{N}$ receptor is a direct target of Glec. Our data, however, do not rule out that Glec could also be involved in modulating activity/ localization of other critical components of $\mathrm{N}$ pathway including its ligands such as Delta. 'In vitro' biochemical analysis will help distinguish between these different likely (and not necessarily mutually exclusive) scenarios.

\section{Materials and Methods}

\section{Genetics}

Combinations of various GAL4 drivers and UAS lines was carried out employing standard genetic methods. cDNA of glec was obtained by reverse transcription from total RNA of Drosophila embryos at stage 10; which was used to generate UAS-glec and UAS glec RNAi lines. Cloning strategies, sequences of primers that were used are described in the supplementary text.

Fly stocks were obtained from various sources: GAL4 drivers used in this study are MS1096-GAL4 (Capdevila et al., 1994); omb-GAL4 (personal communication to Flybase, Calleja, 1996.10.16); ptc-GAL4 (Brand and Perrimon, 1993); sal-GAL4 (Thomas et al., 1995) and ap-GAL4 (Calleja et al., 1996). Other fly strains that were used are argos-lacZ (aos-lacZ, Freeman etal., 1992); E(Spl)mß-lacZ (Cooper etal., 2000); UAS-Galactosyl transferase::RFP (Galt-RFP, Rikhy and Lippincott-Schwartz, personal communication to Flybase); Glec::YFP protein fusion line (obtained from Kyoto Stock Center) and enhancer trap line of glec-GFP (Buszczak et al., 2007).

\section{Histology}

Immunochemical staining on imaginal discs were performed as described earlier (Patel et al., 1989). Antibodies used were rabbit anti-GFP (1:3000; Invitrogen); chicken anti-GFP (1:500; Invitrogen); mouse anti$\beta$-galactosidase (1:500; 40-1a, DSHB); mouse anti-Delta (1:500; Qi et al., 1999); mouse anti-Wingless (1:200; Brook and Cohen, 1996); mouse anti-Cut (1:10 Blochlinger et al., 1993) and Rabbit anti-RFP (1:1000; Invitrogen). Antibodies against Wingless (Wg), Delta (DI), Cut (Ct) and $\beta$-galactosidase ( $\beta$ gal) were obtained from DSHB, lowa, USA. The secondary antibodies conjugated with different fluorophores were obtained from Invitrogen. Fluorescent images were taken using Zeis LSM 710 or Zeiss LSM 780 confocal microscope. Adult wings were processed for imaging as described in Shashidhara et al., (1999).

\section{Acknowledgements}

We thank Bloomington Stock Centre, Development Studies Hybridoma Bank, R Rikhy and G Ratnaparkhi for fly stocks and antibodies, members of LSS lab for discussions and help, G Deshpande and anonymous referees for critical comments on the manuscript; We thank Council of 
Scientific and Industrial Research, India for a research fellowship to NP and Department of Science and Technology (Government of India) for JC Bose Fellowship to LSS.

\section{References}

BAILEY, A M., POSAKONY, J.W. (1995). Suppressor of hairless directly activates transcription of enhancer of split complex genes in response to Notch receptor activity. Genes Dev. 9: 2609-2622.

BLAIR, S.S. (2007). Wing vein patterning in Drosophila and the analysis of intercellular signaling. Annu. Rev. Cell Dev. Biol. 23: 293-319.

BLOCHLINGER, K., JAN, L.Y., JAN, Y.N. (1993). Postembryonic patterns of expression of cut, a locus regulating sensory organ identity in Drosophila. Development 117: 441-450.

BRAND, A., PERRIMON, N. (1993). Targeted gene expression as a means of altering cell fates and generating dominant phenotypes. Development 415: 401-415.

BRAY, S.J. (2006). Notch signalling: a simple pathway becomes complex. Nat. Rev. 7: 678-689.

BROOK, W.J., COHEN, S.M. (1996). Antagonistic interactions between wingless and decapentaplegic responsible for dorsal-ventral pattern in the Drosophila Leg. Science 273: 1373-1377.

BRÜCKNER, K., PEREZ, L., CLAUSEN, H., COHEN, S. (2000). Glycosyltransferase activity of Fringe modulates Notch-Delta interactions. Nature 406: 411-415.

BUSZCZAK, M., PATERNO, S., LIGHTHOUSE, D., BACHMAN, J., PLANCK, J., OWEN, S., SKORA, A.D., NYSTUL, T.G., OHLSTEIN, B., ALLEN, A., WILHELM, J.E., MURPHY, T.D., LEVIS, R.W., MATUNIS, E., SRIVALI, N., HOSKINS, R. A, SPRADLING, A.C. (2007). The carnegie protein trap library: a versatile tool for Drosophila developmental studies. Genetics 175: 1505-1531.

CAPDEVILA, J., GUERRERO, I. (1994). Targeted expression of the signaling molecule decapentaplegic induces pattern duplications and growth alterations in Drosophila wings. EMBO J. 13: 4459-4468.

COOPER, M.T., TYLER, D.M., FURRIOLS, M., CHALKIADAKI, A., DELIDAKIS, C., BRAY, S. (2000). Spatially restricted factors cooperate with notch in the regulation of Enhancer of split genes. Dev. Biol. 221: 390-403.

COUSO, J.P., KNUST, E., MARTINEZ ARIAS, A. (1995). Serrate and wingless cooperate to induce vestigial gene expression and wing formation in Drosophila. Curr. Biol. 5: 1437-1448.

DE CELIS, J., LIGOXYGAKIS, P., PREISS, A., DELIDAKIS, C., BRAY, S. (1996). Functional relationships between Notch, $\mathrm{Su}(\mathrm{H})$ and the bHLH genes of the during imaginal development. Development 122: 2719-2728.

DE CELIS, J.F., BRAY, S. (1997). Feed-back mechanisms affecting Notch activation at the dorsoventral boundary in the Drosophila wing. Development 124:3241-3251.

DE CELIS, J.F., BRAY, S., GARCIA-BELLIDO, A. (1997). Notch signalling regulates veinlet expression and establishes boundaries between veins and interveins in the Drosophila wing. Development 124: 1919-1928.

DE CELIS, J.F., GARCÍA-BELLIDO, A. (1994). Roles of the Notch gene in Drosophila wing morphogenesis. Mech. Dev. 46: 109-122.

DE CELIS, J.F., GARCIA-BELLIDO, A, BRAY, S.J. (1996). Activation and function of Notch at the dorsal-ventral boundary of the wing imaginal disc. Development 122: 359-369.

DE CELIS, F.J. (1998). Positioning and differentiation of veins in the Drosophila wing. Int. J. Dev. Biol. 42: 335-343.

DE CELIS, J.F., DIAZ-BENJUMEA, F.J. (2003). Developmental basis for vein pattern variations in insect wings. Int. J. Dev. Biol. 47: 653-663.

DIAZ-BENJUMEA, F.J., COHEN, S.M. (1995). Serrate signals through Notch to establish a Wingless-dependent organizer at the dorsal/ventral compartment boundary of the Drosophila wing. Development 121: 4215-4225.

DÍAZ-BENJUMEA, F.J., GARCíA-BELLIDO, A. (1990). Behaviour of cells mutant for an EGF receptor homologue of Drosophila in genetic mosaics. Proc. Biol. Sci. 242: 36-44.

FORTINI, M.E. (2009). Notch signaling: the core pathway and its posttranslational regulation. Dev. Cell 16: 633-647.

FREEMAN, M., KLÄMBT, C., GOODMAN, C.S., RUBIN, G.M. (1992). The argos gene encodes a diffusible factor that regulates cell fate decisions in the Drosophila eye. Cell 69: 963-975.

FRISTROM, D., WILCOX, M., FRISTROM, J. (1993). The distribution of PS integrins, laminin A and F-actin during key stages in Drosophila wing development. Development 117: 509-523.

GABAY, L., SEGER, R, SHILO, B. (1997). In situ Activation Pattern of Drosophila EGF Receptor Pathway During Development. Science 277: 1103-1106.

HEITZLER, P., SIMPSON, P. (1993). Altered epidermal growth factor-like sequences provide evidence for a role of Notch as a receptor in cell fate decisions. Development 117: 1113-1123.

HUPPERT, S.S., JACOBSEN, T.L., MUSKAVITCH, M.A. (1997). Feedback regulation is central to Delta-Notch signalling required for Drosophila wing vein morphogenesis. Development 124: 3283-3291.

HURLBUT, G.D., KANKEL, M.W., ARTAVANIS-TSAKONAS, S. (2009). Nodal points and complexity of Notch-Ras signal integration. Proc. Natl. Acad. Sci. USA 106: 2218-2223.

LECOURTOIS, M., SCHWEISGUTH, F. (1995). The neurogenic suppressor of hairless DNA-binding protein mediates the transcriptional activation of the enhancer of split complex genes triggered by Notch signaling. Genes Dev. 9: 2598-2608.

MICCHELLI, C. A, RULIFSON, E.J., BLAIR, S.S. (1997). The function and regulation of cut expression on the wing margin of Drosophila: Notch, Wingless and a dominant negative role for Delta and Serrate. Development 124: 1485-1495.

MOLONEY, D.J., PANIN, V.M., JOHNSTON, S.H., CHEN, J., SHAO, L., WILSON, R., WANG, Y., STANLEY, P., IRVINE, K.D., HALTIWANGER, R.S., VOGT, T.F. (2000). Fringe is a glycosyltransferase that modifies Notch. Nature 406: 369-375.

MONTAGNE, J., GROPPE, J., GUILLEMIN, K., KRASNOW, M. A, GEHRING, W.J., AFFOLTER, M. (1996). The Drosophila Serum Response Factor gene is required for the formation of intervein tissue of the wing and is allelic to blistered. Development 122: 2589-2597.

PALKA, J., SCHUBIGER, M., SCHWANINGER, H. (1990). Neurogenic and antineurogenic effects from modifications at the Notch locus. Development 109: 167-175.

PATEL, N.H., MARTIN-BLANCO, E., COLEMAN, K.G., POOLE, S.J., ELLIS, M.C., KORNBERG, T.B., GOODMAN, C.S. (1989). Expression of engrailed proteins in arthropods, annelids, and chordates. Cell 58: 955-968.

PRASAD, M., MAKHIJANI, K., MADHAVI, M.B., BHARATHI, V., LAL, A., SIRDESAI, G., REDDY, V.R., RAMESH, P., KANNAN, R., DHAWAN, J., SHASHIDHARA, L.S. (2006). Modulation of AP and DV signaling pathways by the homeotic gene Ultrabithorax during haltere development in Drosophila. Dev. Biol. 291: 356-367.

PRICE, J. V, CLIFFORD, R.J., SCHÜPBACH, T. (1989). The maternal ventralizing locus torpedo is allelic to faint little ball, an embryonic lethal, and encodes the Drosophila EGF receptor homolog. Cell 56: 1085-1092.

QI, H., RAND M D, WU X, SESTAN N, WANG W. RAKIC P, XU T, ARTAVANISTSAKONAS, S. (1999). Processing of the Notch Ligand Delta by the Metalloprotease Kuzbanian. Science 283: 91-94.

RULIFSON, E.J., BLAIR, S.S. (1995). Notch regulates wingless expression and is not required for reception of the paracrine wingless signal during wing margin neurogenesis in Drosophila. Development 121: 2813-2824.

SAN JUAN, B.P., ANDRADE-ZAPATA, I., BAONZA, A. (2012). The bHLH factors Dpn and members of the $\mathrm{E}(\mathrm{spl})$ complex mediate the function of Notch signalling regulating cell proliferation during wing disc development. Biol. Open 1: 667-676.

SCHNEPP, B., GRUMBLING, G., DONALDSON, T., SIMCOX, A. (1996). Vein is a novel component in the Drosophila epidermal growth factor receptor pathway with similarity to the neuregulins. Genes Dev. 10: 2302-2313.

SHASHIDHARA, L.S., AGRAWAL, N., BAJPAI, R., BHARATHI, V., SINHA, P. (1999). Negative regulation of dorsoventral signaling by the homeotic gene Ultrabithorax during haltere development in Drosophila. Dev. Biol. 212: 491-502.

SIMCOX,A A, GRUMBLING, G., SCHNEPP, B., BENNINGTON-MATHIAS, C., HERSPERGER, E., SHEARN, A. (1996). Molecular, phenotypic, and expression analysis of vein, a gene required for growth of the Drosophila wing disc. Dev. Biol. 177: 475-489.

STERN, C., BRAVERMAN, T., TIEMEYER, M. (2000). Molecular identification, tissue distribution and subcellular localization of mST3GalV/GM3 synthase. Glycobiology 10: 365-374.

STURTEVANT, M. A, ROARK, M., BIER, E. (1993). The Drosophila rhomboid gene mediates the localized formation of wing veins and interacts genetically with components of the EGF-R signaling pathway. Genes Dev. 7: 961-973. 


\section{N. Prasad and L.S. Shashidhara}

STURTEVANT, M.A., BIER, E. (1995). Analysis of the genetic hierarchy guiding wing vein development in Drosophila. Development 801: 785-801.

THOMAS, U., JONSSON, F., SPEICHER, S.A., KNUST, E. (1995). Phenotypic and molecular characterization of SerD, a dominant allele of the Drosophila gene Serrate. Genetics 139: 203-213.
TIEMEYER, M., GOODMAN, C.S. (1996). Gliolectin is a novel carbohydrate-binding protein expressed by a subset of glia in the embryonic Drosophila nervous system. Development 122: 925-936.

WANG, G., WANG, B., JIANG, J. (1999). Protein kinase A antagonizes Hedgehog signaling by regulating both the activator and repressor forms of Cubitus interruptus. Genes Dev. 13: 2828-2837. 


\section{Further Related Reading, published previously in the Int. J. Dev. Biol.}

Regulation and activity of JNK signaling in the wing disc peripodial membrane during adult morphogenesis in Drosophila Chaturvedula Tripura, Nulu-Prafulla Chandrika,Vutukuru-Nagalakshmi Susmitha, Stéphane Noselli and LS Shashidhara Int. J. Dev. Biol. (2011) 55: 583-590

http://www.intjdevbiol.com/web/paper/103275ct

Patterning the nervous system through development and evolution

Alain Ghysen, Christine Dambly-Chaudière and David W. Raible

Int. J. Dev. Biol. (2010) 54: S1-S14

http://www.intjdevbiol.com/web/paper/103182ag

The Notch pathway in the developing hematopoietic system

Anna Bigas, Àlex Robert-Moreno and Lluís Espinosa

Int. J. Dev. Biol. (2010) 54: 1175-1188

http://www.intjdevbiol.com/web/paper/093049ab

Drosophila castor is regulated negatively by the $U b x$ and abdA genes, but positively by the AbdB gene

Ju-Hyun Ahn, Siuk Yoo, Hyun-Joo Park, Keuk-II Jung, Sang-Hee Kim and Sang-Hak Jeon

Int. J. Dev. Biol. (2010) 54: 1251-1258

http://www.intjdevbiol.com/web/paper/093037ja

Leg regeneration in Drosophila abridges the normal developmental program Manel Bosch, Sarah-Anne Bishop, Jaume Baguña and Juan-Pablo Couso

Int. J. Dev. Biol. (2010) 54: 1241-1250

http://www.intjdevbiol.com/web/paper/093010mb

Evolution of CUT class homeobox genes: insights from the genome of the amphioxus, Branchiostoma floridae

Naohito Takatori and Hidetoshi Saiga

Int. J. Dev. Biol. (2008) 52: 969-977

http://www.intjdevbiol.com/web/paper/072541nt

Function and specificity of Hox genes

David Foronda, Luis F. de Navas, Daniel L. Garaulet and Ernesto Sánchez-Herrero

Int. J. Dev. Biol. (2009) 53: 1409-1419

http://www.intjdevbiol.com/web/paper/072462df

The cellular and genetic bases of organ size and shape in Drosophila Antonio García-Bellido

Int. J. Dev. Biol. (2009) 53: 1291-1303

http://www.intjdevbiol.com/web/paper/072459ag

5 yr ISI Impact Factor $(2013)=2.879$
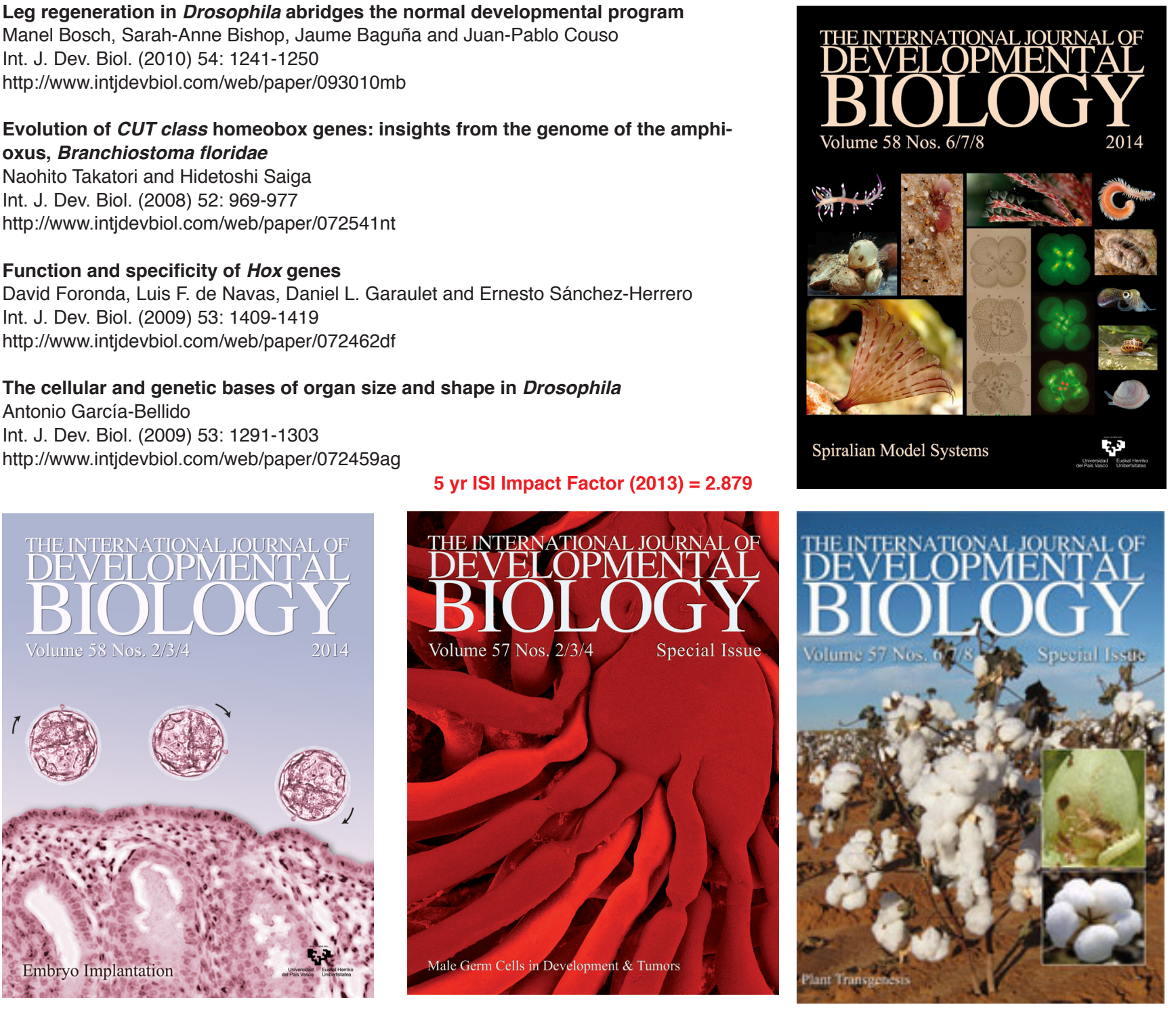